\title{
HERITABLE RUNX1 AND GATA2 MUTATION WITH A VERY RARE GENE VARIANT ASSOCIATED WITH AML-MDS: A CASE REPORT AND REVIEW OF LITERATURE
}

\author{
Shad Ahmed ${ }^{1 *}$, Sarah Alammari ${ }^{2}$, Ahmed Kotb $^{3}$, Shahrukh Hashmi ${ }^{4}$ \\ King Faisal Specialist Hospital and Research Center, Riyadh, Saudi Arabia. \\ Department of Adult Hematology/HSCT. \\ Corresponding Author: shad_ahmed@yahoo.com
}

\section{Abstract:}

A 15 years old boy diagnosed as acute myeloid leukemia (AML) with Myelodysplastic syndrome (MDS) related disorder with history of epistaxis since childhood. The only significant family history of epistaxis of his grandmother only. He presented as pancytopenia in ER with prolonged bleeding from his nose. No family history of malignancy. Additional genetic analysis was performed and identified two heterozygous different gene variant, one is RUNX1 gene for rare germline variant designated c.611G>A, which is predicted to result in the amino acid substitution p. Arg204Gln, another is heterozygous in the GATA2 gene for a variant designated c.554_628delins 16, which is predicted to result in frameshift and premature protein termination (p.Pro185Leufs*77). To our knowledge this variant has not been reported previously in any patient with autosomal dominant GATA2-related disorder but expected to be pathogenic. Germline GATA2 mutations are involved in a group of complex syndromes with overlapping clinical features of immune deficiency, lymphedema and propensity to acute myeloid leukemia or myelodysplastic syndrome (AML-MDS). This case illustrates the importance of recognizing the clinical features for this rare category of AML-MDS and performing the appropriate molecular testing. The diagnosis of heritable gene mutations associated familial AML-MDS has significant clinical implication for the patients and affected families.

Key words: RUNX1, GATA2, Familial acute myeloid leukemia with myelodysplastic syndrome 


\section{Background}

MDS and AML are mostly sporadic hematopoietic malignancies typically affecting older patients. Familial occurrence of MDS or AML is rare, and most of these cases arise in the setting of genetic syndromes associated with increased risks of developing AML or MDS, including several inherited bone marrow failure syndromes. Rare familial cases of MDS and AML have been reported in families without congenital syndromes who carry germ line predisposing mutations. Examination of families with MDS and AML has led to the detection of several inherited mutations in RUNX1 or CEBPA, and more recently GATA2. Here we report a case of young boy with MDS-AML who carry heterozygous in the RUNX1 and GATA2 genes for a rare variant which is never be published before.

\section{Case report:}

A 15-year-old Saudi boy not known to have any previous medical illness presented to the emergency department in local hospital with history of prolonged epistaxis for almost 40 minutes' not preceded by any trauma and an on/off vomiting. He has history of epistaxis since childhood which was never be investigated. No bleeding from other sites, no fever or chills, no rash, asthma, weight loss or easy fatigability. On presentation he has also history of productive cough but no shortness of breath. She had a significant family history epistaxis of his grandmother only, not affecting his siblings or parents or any cousin.

On examination Vital stable, looking well. No skin rash, pallor, no jaundice, no lymphadenopathy or hepatosplenomegaly.

On investigation he has pancytopenia WBCs: 3500/ul, Hb: 93g/l, Platelet: 60,000/ul, Neutrophil 4\%, Monocyte 35\%, atypical cells 10\%. Bone marrow in local hospital revealed hypercellular marrow with trilineage dysplasia, prominent basophilia and Myeloblast 6\%. Patient is referred to our hospital as tertiary care center with pancytopenia and peripheral blast was $6 \%$. BM was repeated which revealed atypical monocytosis and significant trilineage dysplasia and blast was $22 \%$.

Flow cytometry immunophenotyping performed on the bone marrow aspirate revealed a myeloid blast population that was partial CD34+, CD117+, HL-DR+, CD11b+ CD15 partial+, c- 
MPO+, CD13+ and CD33+. The flow cytometry results support the diagnosis of acute myeloid leukemia. Cytogenetic analysis performed on fresh bone marrow aspirate revealed 45, XY, 7[20]. FISH is positive for monosomy 7 in 30/100. Based on the morphologic and cytogenetic findings, the patient was diagnosed with acute myeloid leukemia with myelodysplasia related changes. Molecular tests for FLT3 ITD, NPM1, CEBPA and KIT genes were negative performed on DNA extracted from fresh bone marrow aspirates. BCR-ABL1 and JAK-2 was also negative. Chromosomal breakage analysis was also negative.

The sample (whole blood) is sent for molecular analysis of MDS/AML Sequencing panel for Next Generation sequence (NGS) to Mayo clinic USA. The result revealed that patient is heterozygous in the RUNX1 gene for rare variant designated c.611G>A, which is predicted to result in the amino acid substitution p. Arg204GIn. This variant is likely to be primary cause of disease.

This patient is also heterozygous in the GATA2 gene for a variant designated c.554_628delins 16 , which is predicted to result in frameshift and premature protein termination (p.Pro185Leufs*77). To our knowledge this variant has not been reported previously in any patient with autosomal dominant GATA2-related disorder but expected to be pathogenic.

The patient is considered high risk AML with MDS related changes with GATA2/RUNX1 variant with monosomy 7 . The patient has been offered 3+7 (Idarubicin $12 \mathrm{mg} / \mathrm{m} 2$ and Cytarabine 100 $\mathrm{mg} / \mathrm{m} 2$ ). Day $14 \mathrm{BM}$ is hypocellular and no residual blast. D+28 is hypercellular but with $6 \%$ blast in bone marrow but D+34 BM hypercellular and no blast. FISH is still positive for monosomy 7 . The patient is considered morphological remission without cytogenetic or molecular remission. The patient is considered Allo-SCT but no matched sibling donor is available. Patient has local MUD available and offered IDAC (Intermediate dose Ara-C) to bridge for MUD Allo-SCT. Although it was recommended to confirm the germ line nature of the GATA2 mutation by submitting additional material such as a skin biopsy or a buccal swab for germline GATA2 testing, it was not performed due to the patient's poor condition from persistent chronic infection. Other family members declined testing for GATA2 mutations.

\section{Discussion:}


Familial syndromes in which MDS/AML is a primary feature include familial platelet disorder with predisposition to myeloid malignancy (FPDMM) associated with germline RUNX1 mutations characterized by mild to moderate bleeding tendencies and impaired platelet aggregation [1] (Owen et al.2008. PubMed ID: 18173751). The incidence of MDS/AML in patients with RUNX1 variants is over $40 \%$ with wide ranging age of onset from childhood to adults in their 70s (Churpek et al.2012. PubMed ID:23258901). RUNX1 point mutations in leukemia were first identified in 1999 [2]. Many subsequent studies documented frequent somatic mutations in RUNX1 in MDS, AML, ALL, and chronic myelomonocytic leukemia (CMML) [3]. Germline mutations of RUNX1 are associated with familial platelet disorder with associated myeloid malignancy (FPDMM) [4]. The RUNX1 gene encodes a transcription factor critical for normal hematopoiesis. Causative variants in RUNX1 are most often missense, nonsense, or frameshift variants resulting in premature protein truncation with possible dominant negative effects. FPDMM (OMIM \#601399) is an autosomal-dominant disorder with variable penetrance genetically defined by the presence of germline RUNX1 mutation. RUNX1 encodes one of the $\alpha$ subunits of a core-binding transcription factor and plays a critical role in hematopoiesis, myeloid differentiation and platelet function [5]. FPDMM is characterized by abnormalities in platelet number and/or function, namely defective release of $\delta$ granules, and a propensity to develop early-onset MDS/AML or, rarely, T-lymphoblastic leukemia/ lymphoma. Until now, about 50 pedigrees with germline RUNX1 mutations have been reported [6].

The result of NGS of our patient revealed heterozygous in the RUNX1 gene for rare variant designated c.611G>A, which is predicted to result in the amino acid substitution p. Arg204GIn. This variant has been reported as a germline variant in two families with history of autosomal dominant familial platelet disorder familial platelet disorder that progressed to acute leukemia in some of the family members (aka p.Arg177GIn in Preudhomme et al.2009 PubMed ID: 19357396; Latger-Cannard et al. 2016. PubMed ID: 27112265)). This variant is likely to be primary cause of disease.

Expression of GATA2 is significantly higher in AML compared to normal bone marrow, and is an adverse indicator of prognosis [8]. Mutations involving GATA2 coding sequence are not common in sporadic AML cases, and are frequently associated with a more specific subgroup of AML with 
normal cytogenetics and biallelic CEBPA mutations. In these cases, somatic mutation of GATA2 is likely a secondary event in the leukemogenesis 7,9-11]. However, germline GATA2 mutations have a very different oncogenic role. Germline GATA2 mutations are involved in a group of complex syndromes with overlapping clinical features, including a rare genetic disorder called MonoMAC, Emberger syndrome and familial AML following MDS. These diverse syndromes may reflect different clinical manifestations of the common underlying defect of GATA2 deficiency. MonoMac is a complex congenital immunodeficiency characterized by persistent and profound peripheral monocytopenia, B- and NK-cell lymphocytopenia, near absence of dendritic cells and increased susceptibility to mycobacterium or papilloma virus infections [12-14]. Emberger syndrome is characterized by primary lymphedema inherited in an autosomal dominant pattern $[15,16]$. Both syndromes are associated with a predisposition to acute myeloid leukemia and myelodysplastic syndrome. GATA2 has recently been recognized as a MDS-AML predisposition gene, in addition to the previously reported $R U N X 1$ and CEBPA. Our patient is also heterozygous in the GATA2 gene for a variant designated c.554_628delins 16, which is predicted to result in frameshift and premature protein termination (p.Pro185Leufs*77). To our knowledge this variant has not been reported previously in any patient with autosomal dominant GATA2-related disorder but expected to be pathogenic. Similar variants resulting in premature protein termination and located throughout the GATA2 gene have been reported in several patients with GATA2 related disorders and predisposition to acute myeloid leukemia (Osterbaard et al.,2011. PubMed ID:21892158; Wlodarskl et al., 2016, PubMed ID: 26702063). The p. Pro185Leufs*77 variant found in the current patient is consistent with being a primary cause of the disease.

Heritable GATA2 mutations associated with familial myelodysplastic syndrome and acute myeloid leukemia have only been described recently. There is no clear correlation between the genotype and clinical outcome. Based on limited cases reported in the literature, the affected individuals usually have a poor outcome unless successfully transplanted $[11,17]$. A recent report of GATA2 p.Thr354Met mutation was observed in a pedigree in which 2 first-degree cousins developed high-risk myelodysplastic syndrome with monosomy 7. A recent study reported six patients who underwent allogeneic stem cell transplant for GATA2 deficiency had excellent outcomes except one who died from infection [18]. Other anecdotal reports implied a less ideal outcome [17]. It is likely other secondary genetic event such as $A S X L$ mutation and loss of chromosome 7 confer a poorer prognosis. 
It is import to identify familial cases of AML-MDS and test the heritable mutations. A complete clinical and family history is a clue to recognizing patients with an inherited predisposition to myeloid neoplasm. Germline testing should be considered in a family with more than one close relatives affected by $A M L-M D S$ or in patients with early onset disease. A recent study based on large population based registry data did not show that relatives of patients with AML-MDS are at increased risk of hematologic tumor, but there is a significant increased risk of AMLMDS and other myeloid malignancies among first degree relatives of patients diagnosed at younger than age 21 years [19]. This suggests that young age at the onset of disease is probably the most useful indicator to look for inherited factors in developing AML-MDS. Germline testing should be performed in specimens containing only the nonleukemic cells such as skin fibroblasts. Buccal swab or saliva samples are acceptable; though these may contain lymphocytes derived from hematopoietic stem cells. The detection of an underlying germ line mutation has significant implications for clinical practice. Due to the poor outcomes in the reported AML cases with GATA2 mutations, aggressive and early intervention such as allogeneic stem cell transplant should be considered. Family members with identified germline mutations should be avoided as stem cell donors. Although there is no direct data, family members under consideration for being HSCT donors should be tested to exclude mutations in the same predisposition gene, due to the theoretical risk of developing AML in the future from the graft with the same mutation.

\section{Conclusion:}

In addition to RUNX1 and CEBPA, GATA2 gene mutations have only been recently reported involved in familial AML-MDS. Here we reported heterozygous RUNX1 gene variant and very rare heterozygous GATA2 gene variant which is never be published previously in any patient with autosomal dominant GATA2 related disorder. Heritable gene mutations as a predisposition gene to AML-MDS are likely under recognized, but have significant implication in managing the patients and the affected families. It is important to recognize this rare entity, be familiar with the clinical features, and seek appropriate laboratory testing when there is a clinical concern. This rare entity recognizes that patient should be undergoing Allo-SCT as soon as possible.

\section{Consent:}


Written informed consent was obtained from the patient's next kin for publication of this case report and any accompanying images.

\section{Competing interests}

I have no competing interests.

\section{References:}

1. Gergen JP, Butler BA. Isolation of the Drosophila segmentation gene runt and analysis of its expression during embryogenesis. Genes Dev. 1988;2(9):1179-1193.

2. Osato M, Asou N, Abdalla E, et al. Biallelic and Heterozygous Point Mutations in the Runt Domain of the AML1/PEBP2alphaB Gene Associated with Myeloblastic Leukemias. Blood. 1999;93(6):1817-1824.

3. Osato M. Point mutations in the RUNX1/AML1 gene: another actor in RUNX leukemia. Oncogene. 2004;23(24):4284-4296.

4. Song WJ, Sullivan MG, Legare RD, et al. Haploinsufficiency of CBFA2 causes familial thrombocytopenia with propensity to develop acute myelogenous leukaemia. Nat Genet. 1999;23(2):166-175.

5. Gergen JP, Wieschaus EF. The localized requirements for a gene affecting segmentation in Drosophila: analysis of larvae mosaic for runt. Dev Biol. $1985 ; 109(2): 321-335$.

6. De Braekeleer E, Douet-Guilbert N, Morel F, Le Bris MJ, Ferec C, De Braekeleer M. RUNX1 translocations and fusion genes in malignant hemopathies. Future Oncol. 2011;7(1):77-91.

7. Luesink M, Hollink IH, van der Velden VH, Knops RH, Boezeman JB, de Haas V, Trka J, Baruchel A, Reinhardt D, van der Reijden BA, van den Heuvel-Eibrink MM, Zwaan CM, Jansen $\mathrm{JH}$. High GATA2 expression is a poor prognostic marker in pediatric acute myeloid leukemia. Blood. 2012; 120:2064-2075. doi: 10.1182/blood-2011-12-397083.

8. Bullinger L, Dohner K, Bair E, Frohling S, Schlenk RF, Tibshirani R, Dohner H, Pollack JR. Use of gene-expression profiling to identify prognostic subclasses in adult acute myeloid leukemia. N Engl J Med. 2004; 350:1605-1616. doi: 10.1056/NEJMoa0310468. 
9. Fasan A, Eder C, Haferlach C, Grossmann V, Kohlmann A, Dicker F, Kern W, Haferlach T, Schnittger S. GATA2 mutations are frequent in intermediate-risk karyotype AML with biallelic CEBPA mutations and are associated with favorable prognosis. Leukemia. 2013; 27:482-485. doi: $10.1038 /$ leu.2012.174.

10.Grossmann V, Haferlach C, Nadarajah N, Fasan A, Weissmann S, Roller A, Eder C, Stopp E, Kern W, Haferlach T, Kohlmann A, Schnittger S. CEBPA double-mutated acute myeloid leukaemia harbours concomitant molecular mutations in $76.8 \%$ of cases with TET2 and GATA2 alterations impacting prognosis. Br J Haematol. 2013; 161:649-658. doi: 10.1111/bjh.12297.

11. Hahn CN, Chong CE, Carmichael CL, Wilkins EJ, Brautigan PJ, Li XC, Babic M, Lin M, Carmagnac A, Lee YK, Kok CH, Gagliardi L, Friend KL, Ekert PG, Butcher CM, Brown AL, Lewis ID, To LB, Timms AE, Storek J, Moore S, Altree M, Escher R, Bardy PG, Suthers GK, D'Andrea RJ, Horwitz MS, Scott HS. Heritable GATA2 mutations associated with familial myelodysplastic syndrome and acute myeloid leukemia. Nat Genet. 2011; 43:1012-1017. doi: 10.1038/ng.913.

12. Vinh DC, Patel SY, Uzel G, Anderson VL, Freeman AF, Olivier KN, Spalding C, Hughes S, Pittaluga S, Raffeld M, Sorbara LR, Elloumi HZ, Kuhns DB, Turner ML, Cowen EW, Fink D, Long-Priel D, Hsu AP, Ding L, Paulson ML, Whitney AR, Sampaio EP, Frucht DM, DeLeo FR, Holland SM. Autosomal dominant and sporadic monocytopenia with susceptibility to mycobacteria, fungi, papillomaviruses, and myelodysplasia. Blood. 2010; 115:1519-1529. doi: 10.1182/blood-2009-03-208629. [

13. Hsu AP, Sampaio EP, Khan J, Calvo KR, Lemieux JE, Patel SY, Frucht DM, Vinh DC, Auth RD, Freeman AF, Olivier KN, Uzel G, Zerbe CS, Spalding C, Pittaluga S, Raffeld M, Kuhns DB, Ding L, Paulson ML, Marciano BE, Gea-Banacloche JC, Orange JS, Cuellar-Rodriguez J, Hickstein DD, Holland SM. Mutations in GATA2 are associated with the autosomal dominant and sporadic monocytopenia and mycobacterial infection (MonoMAC) syndrome. Blood. 2011;118:2653-2655. doi: 10.1182/blood-2011-05356352 .

14. Bigley V, Haniffa M, Doulatov S, Wang XN, Dickinson R, McGovern N, Jardine L, Pagan S, Dimmick I, Chua I, Wallis J, Lordan J, Morgan C, Kumararatne DS, Doffinger R, van der Burg M, van Dongen J, Cant A, Dick JE, Hambleton S, Collin M. The human 
syndrome of dendritic cell, monocyte, B and NK lymphoid deficiency. J Exp Med. 2011; 208:227-234. doi: 10.1084/jem.20101459.

15. Ostergaard P, Simpson MA, Connell FC, Steward CG, Brice G, Woollard WJ, Dafou D, Kilo T, Smithson S, Lunt P, Murday VA, Hodgson S, Keenan R, Pilz DT, MartinezCorral I, Makinen T, Mortimer PS, Jeffery S, Trembath RC, Mansour S. Mutations in GATA2 cause primary lymphedema associated with a predisposition to acute myeloid leukemia (Emberger syndrome) Nat Genet. 2011; 43:929-931. doi: 10.1038/ng.923.

16. Mansour S, Connell F, Steward C, Ostergaard P, Brice G, Smithson S, Lunt P, Jeffery S, Dokal I, Vulliamy T, Gibson B, Hodgson S, Cottrell S, Kiely L, Tinworth L, Kalidas K, Mufti G, Cornish J, Keenan R, Mortimer P, Murday V. Lymphoedema Research Consortium. Emberger syndrome-primary lymphedema with myelodysplasia: report of seven new cases. Am J Med Genet A. 2010;152A:2287-2296. doi: 10.1002/ajmg.a.33445.

17. Bodor C, Renneville A, Smith M, Charazac A, Iqbal S, Etancelin P, Cavenagh J, Barnett MJ, Kramarzova K, Krishnan B, Matolcsy A, Preudhomme C, Fitzgibbon J, Owen C. Germ-line GATA2 p.THR354MET mutation in familial myelodysplastic syndrome with acquired monosomy 7 and ASXL1 mutation demonstrating rapid onset and poor survival. Haematologica. 2012; 97:890-894. doi: 10.3324/haematol.2011.054361.

18. Cuellar-Rodriguez J, Gea-Banacloche J, Freeman AF, Hsu AP, Zerbe CS, Calvo KR, Wilder J, Kurlander R, Olivier KN, Holland SM, Hickstein DD. Successful allogeneic hematopoietic stem cell transplantation for GATA2 deficiency. Blood. 2011; 118:37153720. doi: 10.1182/blood-2011-06-365049.

19. Goldin LR, Kristinsson SY, Liang XS, Derolf AR, Landgren O, Bjorkholm M. Familial aggregation of acute myeloid leukemia and myelodysplastic syndromes. J Clin Oncol. 2012;30:179-183. doi: 10.1200/JCO.2011.37.1203. 